\title{
AUTOMATIVE UNWINDING OF WASTE PAPER FROM REEL SPOOLS
}

Paper industry deals with procedures for conceptual and final design of a machine intended for unwinding paper that remains on reels during a certain phase of paper producing. Design procedure of the machine is a subject of this paper. The machine was designed as a mechatronic unit consisting of a mechanical part, an electric part and a pneumatic part. 3D CAD/CAM system Pro/ENGINEER was used for the design of the mechanical part. For the automation processes the PLC unit connected with the frequency changing unit and asynchronous drive were used as a central drive for the unwinding machine.

\section{Introduction}

In order to make production of paper faster, more effective and environmental friendlier, the paperwork in Ružomberok defined a task, the solution of which would approximate its production technology chain toward aforementioned goals. So far manually performed removal of wound-up rest of web paper that remains on a reel spool after a web unwinding - during a paper production would be automated. The paper remains wound-up on a reel spool due to a used technology of production and due to production process tolerances. This unwound paper, the diameter of which varies, can not go for subsequent processing. Thus it is necessary to remove it from a reel and put it back to the production, recycle it. A former method of removing the paper from a reel was manual. With the use of knife, an operator had to cut the remaining paper off a reel and store the removed paper in a container from where it went for further processing. It is a time-consuming operation. Taking into consideration the weight and length of a reel, it is also physically hard.

The objective of the defined task was to minimise the manual operation of the removal of the rest of paper from a reel and speed up the process. The overall objective of the task was to design and to manufacture a fully automatic machine that would be able to unwind remained paper from a reel and would direct it for a recycling process. The emptying a reel must be done without damaging a reel itself. Furthermore, the machine must be able to place the removed paper on a conveyor that will transfer it for a recycling process and must be able to collect emptied reels at one particular place. As to a machine operator, the only activity he/she will perform will be loading rolls intended for unwinding and to unload empty reels.

The submitter of the task defined a set of initial parameters for the unwinding machine.
The parameters are:

- the width of a roll before unwinding: max. $400 \mathrm{~mm}$

- the length of a reel: max. $2200 \mathrm{~mm}$

- the diameter of a reel: $176 \mathrm{~mm}$

- the unwinding speed: $\max .150 \mathrm{~m} / \mathrm{min}$

- voltage: 3 x $400 \mathrm{~V}, 50 \mathrm{~Hz}$

- compressed air pressure: max. 6 bar

- operating environment definition: standard, basic according the STN 330300 vol.3.1.1

The device can be divided into three basic parts:

- a mechanical part consisting of a machine frame, movable mechanisms, a machine covering,

- an electric part consisting of electric drive and power supply as a power part and a control part with PLC computer and sensors,

- a pneumatic part with pneumatic cylinders, valves and devices for compressed air parameters control.

\section{Mechanical part of the machine}

A procedure, in which the initial information is processed with respect to function requirements and in which also device parameters and working environment information are set up, is called a design process. The design process is divided into several steps. In the case of design of a machine intended for removing rest of paper off a reel spool, the steps were applied as well.

In the first phase, based on the submitter's specification of the task, general requirements for the machine capabilities and features were determined. Accordingly mechanical characteristics of the device were defined. The definition took into consideration the following attributes: the maximum weight and diameter of a roll to be unwound, need of using a fork lift for loading rolls, necessity of connection to the actual technical and technological

\footnotetext{
* P. Lehocký ${ }^{1}$, R. Kohár ${ }^{2}$, S. Hrček ${ }^{2}$, J. Podhorský ${ }^{2}$, B. Surmová ${ }^{3}, \check{S}_{\text {S. Medvecký }}^{2}$, A. Hrčeková2

${ }^{1}$ Faculty of Electronical Engineering, University of Žilina, e-mail: Pavel.Lehocky@fel.utc.sk

${ }^{2}$ Faculty of Mechanical Engineering, University of Žilina

${ }^{3}$ Rectors Office of the University of Žilina
} 
infrastructure (electricity, compressed air). Also work safety conditions according STN must have been respected.

In the next step there were several solutions proposed to address the task of automatic removal of the rest of unwound paper. The solution had to consider changing length and diameter of a roll and to respect the requirements for unwinding speed and avoid damaging emptied reels.

Among proposed solutions, there was one in which the usual cutting procedure was considered. In order to remove the left paper from a reel by cutting it off, this solution, however, could not guarantee that during the cutting operation a reel would not be damaged. Prevention of damaging a reel is difficult due to a variable diameter of a reel that varies between $176 \mathrm{~mm}$ to $400 \mathrm{~mm}$ or even more Such a solution requires the reel fixation and smooth regulation of depth of cut according to the actual diameter. The analysis and a feasibility study for this machine design showed that the expenditure for such a device would be excessive due to complicated loading and reel fixation mechanisms. The adjusting of the cut was problematic and the reliability of the cutting procedure was insufficient. Therefore this option of the task solution could not be applied.

Trying to find a reliable and effective solution for removing the rest of wound-up paper from a reel it was found out that the most effective way for emptying reels would be unwinding the left paper. Several options for unwinding were considered and analysed during the design process. In the end, using rotating cylinders or V-belts, as presented in Fig. 1, was considered the best and also the simplest solution.

Further analysis showed that rotating cylinders, used, for instance, for unwinding metal sheets, could not be accepted due to high speed required for paper unwinding. For high unwinding speed the additional device for a roll fixation is needed. Another additional device is necessary for releasing and transferring empty reels to storage. Assuming that the maximum weight of a roll before unwinding is $200 \mathrm{~kg}$, and providing that an additional device for fixation and another one for after-unwinding manipulation would be needed, the mechanism (rotating cylinders and related devices) should be very robust. Therefore cost of material for such a device would negatively affect the final price of the device.
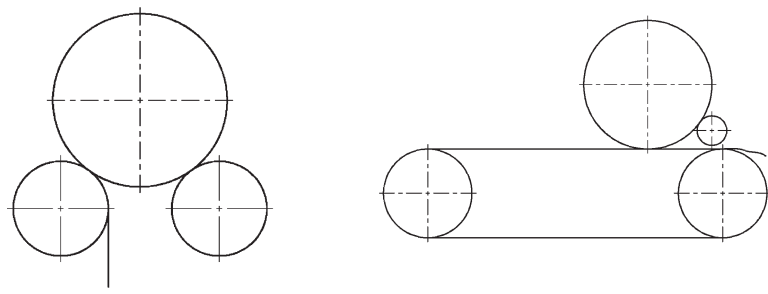

Fig. 1 Unwinding of the rest roll by rotational cylinders and V-belts principles
As the most appropriate solution, a V-belt solution was chosen as a principle for a machine design [2]. V-belt solution allows achieving speed required for unwinding and allows easy loading of rolls and unloading empty reels. A roll is placed in a system of Vbelts. During loading it is important to place a roll on belts carefully in correct orientation. Owing to V-belts movement the roll is transferred to supporting cylinders, leans against them and the roll starts unwinding. The paper is directed under supporting cylinders and transported out of the unwinding space to a conveyor.

During the design process it is important to design particular parts and mechanisms of the machine. They are customised according the shape and dimension of the machine and they form groups. The proposed unwinder consists of two basic groups: a machine frame and an unwinding module. The machine frame consists of a loading plate for a roll, a device for loading a single roll to the unwinding module (a guide or a loader), a frame with supporting and guiding reels, covers, and storage for empty reel spools. Unwinding module consists of a frame of unwinding module and a movable V-belt part.

The design of the machine was done with CAD system Pro/ENGINEER Wildfire 2.0.

The system enables presenting the initial design of unwinding machine as a virtual 3D model. The initial 3D model of the machine is shown in Fig. 2.

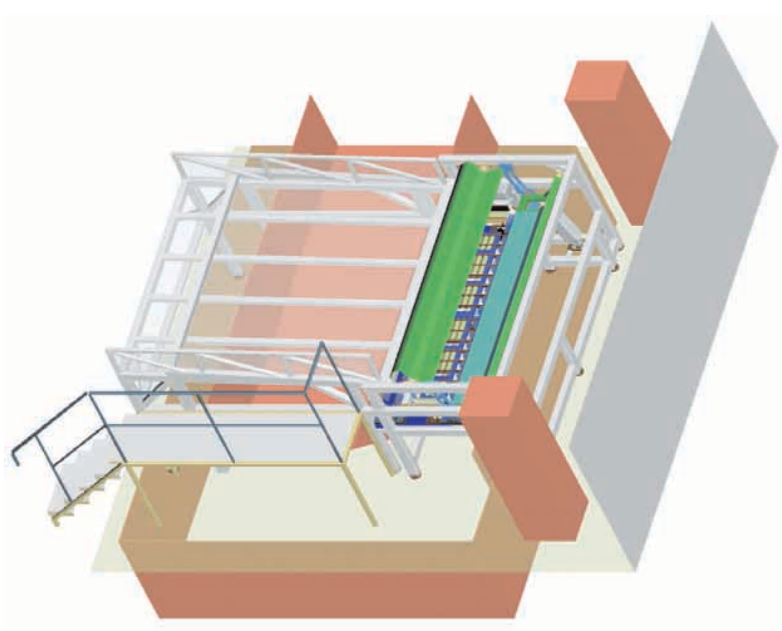

Fig. 2 Initial design of machine

Fig. 3 presents the final 3D model of the machine. In accordance with the demand of the customer, a storage box replaces a transportation box for empty reels with possibility of tying empty reels together. A frame of the machine is manufactured from welded steel profiles, which form a construction in which the particular mechanisms are installed. A loading ramp is used for loading rolls that are intended for unwinding. A guide - a device for loading one roll at a time on unwinding belts - prevents other rolls from being loaded if there is a roll already being unwound and at the same time it prevents the roll from dropping out of the 
belts during the unwinding process. The function of the guide is to ensure that no other roll will interfere with a roll being just unwound. Supporting reels ensure rotation of a roll and consequent unwinding of the paper. Guiding reels ensure that the unwound paper will not wind back to the unwinding space. Supporting and guiding reels are placed in the same area. The unwinder has a safety cover, which guarantees that no foreign element or a person will get in the unwinding area. Thus injuries are prevented. The storage space under the loading plate is used for storing empty reels.
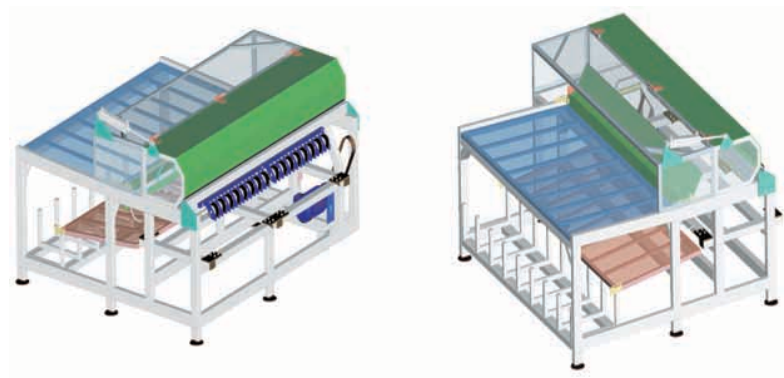

Fig. 3 Final from of frame

An unwinding device - Fig. 4 - consists of a frame assembled from aluminium profiles. Bearing boxes are placed here. A rotational part consists of two shafts, driving and driven, both equipped with a set of V-belt pulleys.

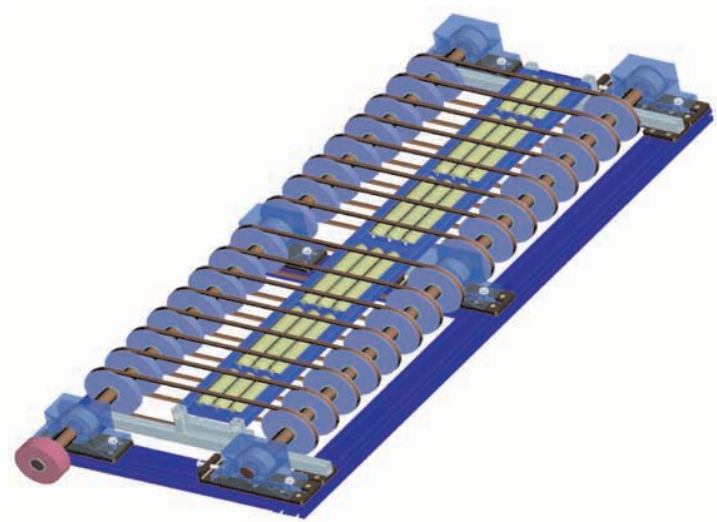

Fig. 4 Final form of unwinde

The final 3D model of the unwinding machine with the incorporated unwinding module is presented in Fig. 5.

CAD system Pro/ENGINEER allows not only creating 3D model of a designed device but is capable also of verifying functionality of the system by animation and simulation of the designed solution. This feature of the Pro/ENGINEER system was used for the design and verification of the functionality of the guide (loader) device, as well as the safety cover, as it is presented in Fig. 6 .

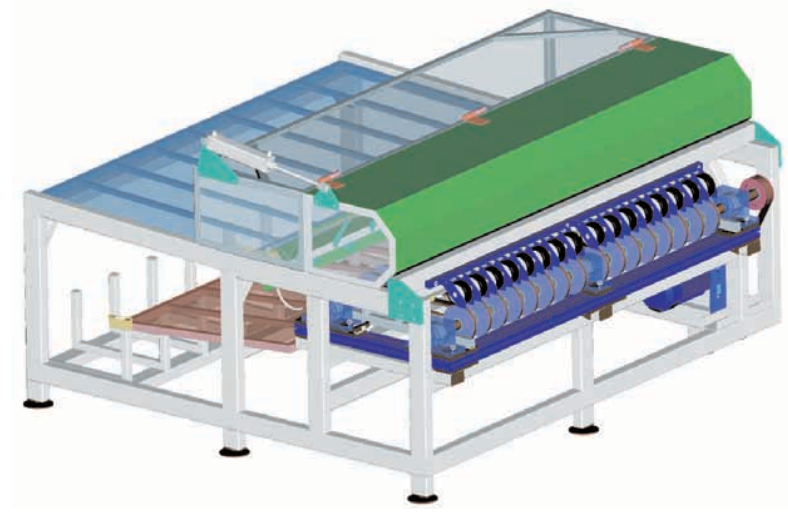

Fig. 5 Final 3D model of the machine
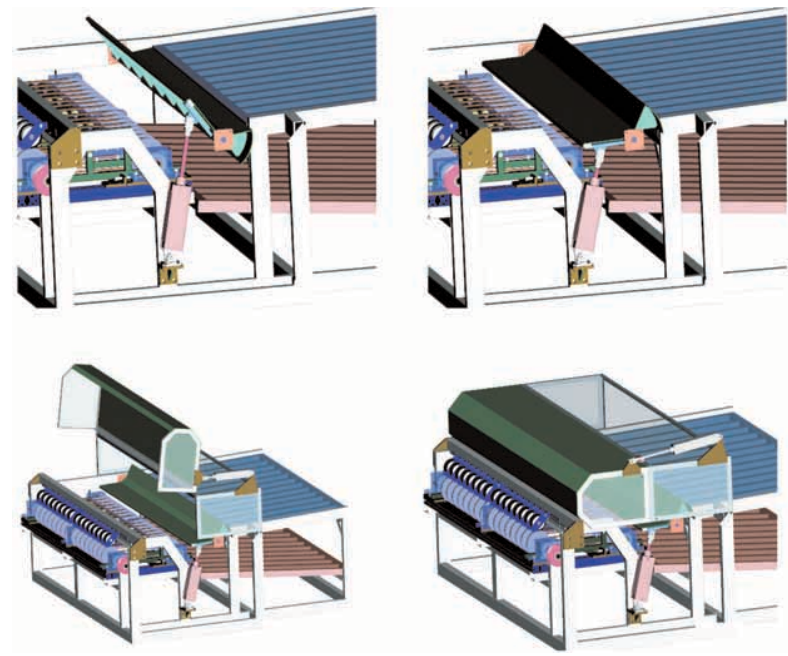

Fig. 6 The guide device simulation and the simulation sof the safety cover

During the process of a roll unwinding it is necessary to guarantee continuous rotation of the roll. The thickness of the unwinding paper changes during the unwinding process and so does the

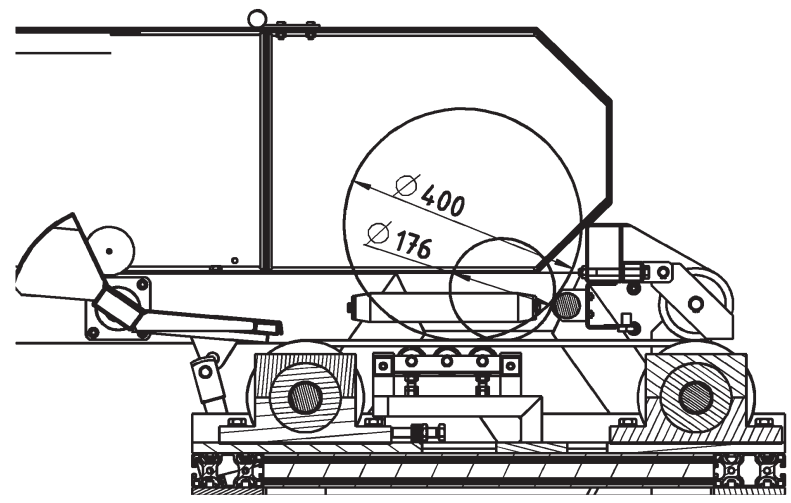

Fig. 7 Simulation of unwinding 
points of contact between supporting reels and paper. Bearing in mind a changing diameter of a roll, in order to meet the condition of continuous rotation, the supporting reels must be placed in an appropriate way. Fig. 7 shows the simulation.

Reliable functioning of the machine is achieved through guaranteeing all pre-defined dimensions and tolerances during the machine manufacturing. Accuracy is important especially regarding to movable mechanisms and their placement. The guide device must be positioned aligned. As far as the unwinding unit, the position and proper alignment of shafts must be guaranteed as well. Each of the shafts lies in three bearing boxes. In case of inaccurate position of either of the shafts some bearing can be damaged due to inappropriate alignment. Alignment of the shafts must be measured carefully before putting the device into operation.

The measurement was done by 3D measuring device FARO Laser Scan Arm. The device is presented in Fig. 8. The FARO Laser Scan Arm is a device with no need for special laboratory conditions.

The measurement of an existing device or a product carried out by FARO Laser Scan Arm is called 3D scanning. This method of collecting data is called Reverse Engineering. Reverse Engineering enables transformation of a real existing object into a virtual object. The result of the 3D scanning procedure is usually a data cloud, which is transformed to the regular surfaces and volumes by means of specialised software.

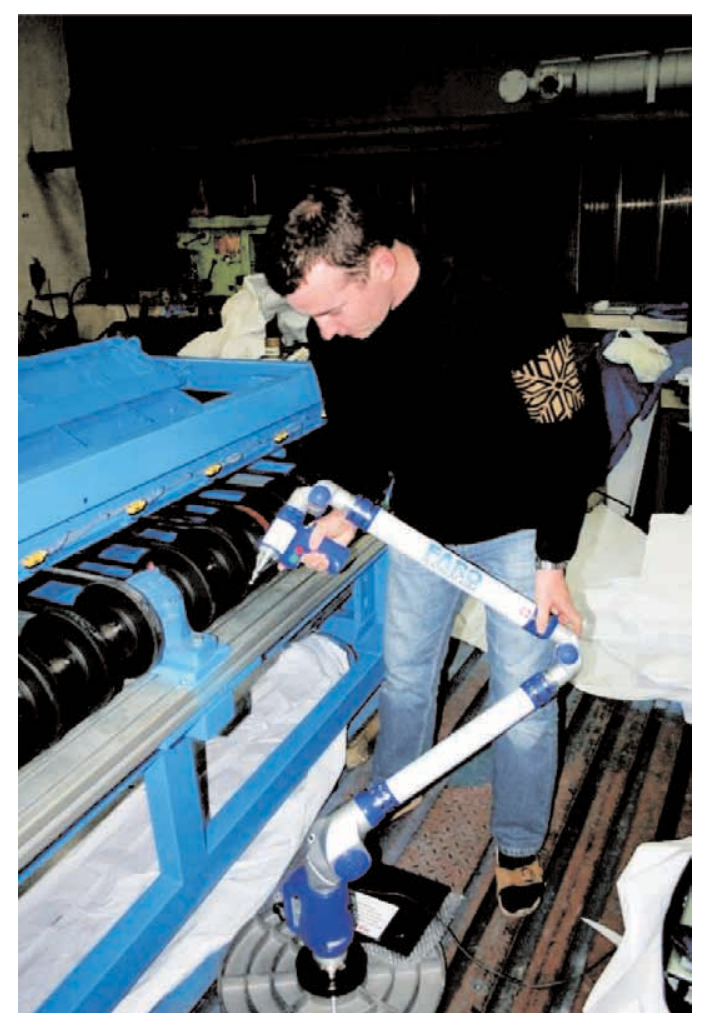

Fig. 8 Measuring of the object with FARO
In the process of the machine design, Reverse Engineering [3] was used for control of the shaft alignment. The scanned data were processed in PolyWorks software. PolyWorks enables to compare measured parameters of a real object with the virtual $3 \mathrm{D}$ model. Fig. 9 shows the example of the output of the PolyWorks software. Grey colour represents 3D virtual model of a shaft lying on bearing boxes. The colourful object projected in a spectrum of colours represents a real scanned shaft. Each particular colour of the spectrum gives information about how much the real object differs from the virtual one. Such procedure allows adjusting the shafts into desired position.
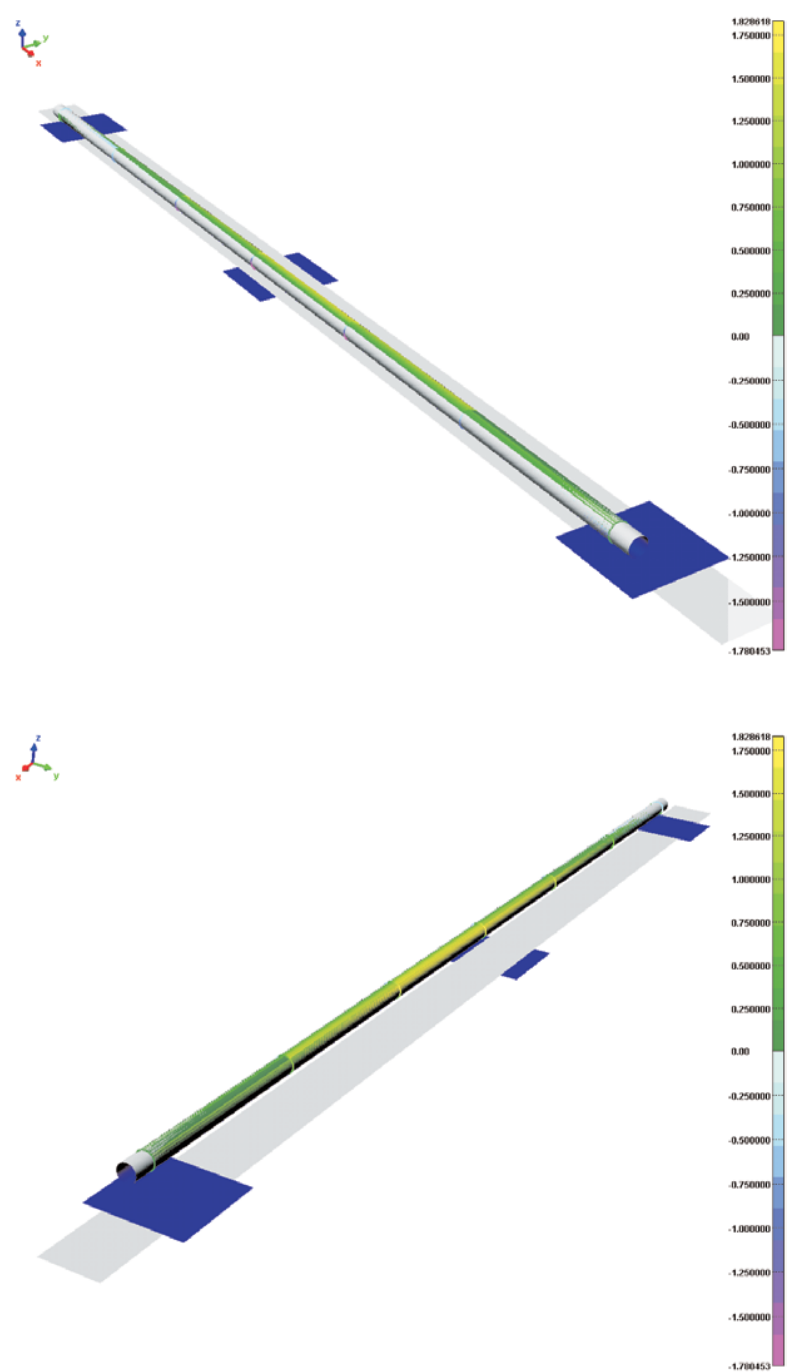

Fig. 9 Graphic outputs from PolyWorks software

\section{Electric part of the machine}

In order to fully meet the customer's requirements, attention is given to all parts of the machine. An electric part of the machine is tailored accordingly and connected to the mechanical part. It is 
composed of driving units and control parts. The function of the driving part is to put the mechanisms of unwinding unit into movement. The control part controls the mechanisms in accordance with the technological demands. The integrated parts of the electrical part are sensors, switches, circuit breakers and electro installation. Electric part of designed machine is divided into two parts:

- a power unit consisting of electric drive, a frequency changer, control elements (switches, fuses, main switch, emergency switch, ...),

- a control part consisting of a PLC computer unit, control elements (switches), sensors, output action elements (electromagnetic valves, signalization,...).

The design of the electric part of the unwinding machine must correspond to the basic data requested by the customer:

- supply voltage - 3PEN $\sim 50 \mathrm{~Hz} 400 \mathrm{~V} / \mathrm{TN}-\mathrm{S}$,

- operating environment - standard, basic according STN 330300.

The design of the electric part of the unwinder consist of a design of a switchboard with all its parts optimally arranged and connected and a design of electric circuits and connections of all instruments and electric devices located in the machine.

According to the task definition, the required unwinding speed of the machine is $150 \mathrm{~m} / \mathrm{min}$. The speed and a total moment of inertia of the system calculated from rotation of electro drive shaft determine parameters of the electro drive, such as power output, turns per minute, torque moment. It is necessary to ensure that the electro drive will reach the requested turns per minute under load in such time period that overheating of the electric drive will not occur. For asynchronous drives with intermediate power range such effect can occur when the moment of inertia is $20-30$ times higher than moment of inertia of an armature. For a twopole asynchronous electric drive the critical value occurs when moment of inertia is $8-12$ times higher than moment of inertia of an armature [1]. The effect of overheating of the asynchronous drive is caused by the fact, that during acceleration of the drive at high load the power losses are 25 - 35 times higher than losses of a drive running at normal load. The high losses cause that the drive winding reaches the highest allowed temperature within 10 - 15 seconds. In case of large moment of inertia of the system the drive acceleration time exceeds $10-15$ seconds, which leads to immediate damage of the drive isolation. With respect to the above mentioned facts and taking into consideration the input parameters and safety limit of 1,3 , a drive with economic asynchronous motor with integrated front gearbox is considered as the best option, as shown in Fig. 10. This type of asynchronous motor differs from others by a cage of a rotor. In the case of the economic asynchronous motor the cage is manufactured from copper. The use of copper reduces the losses in the motor, increases the efficiency of the motor and decreases the power consumption with respect to the requested output

Following are the parameters of the asynchronous motor: power is $4 \mathrm{~kW}$, nominal current at $400 \mathrm{~V}$ is $8,1 \mathrm{~A}$, nominal turns per minute is $1460 \mathrm{rpm}$, nominal torque moment is $26,9 \mathrm{Nm}$. As to the gearbox, its input parameter is gear ratio of 5, 64 .

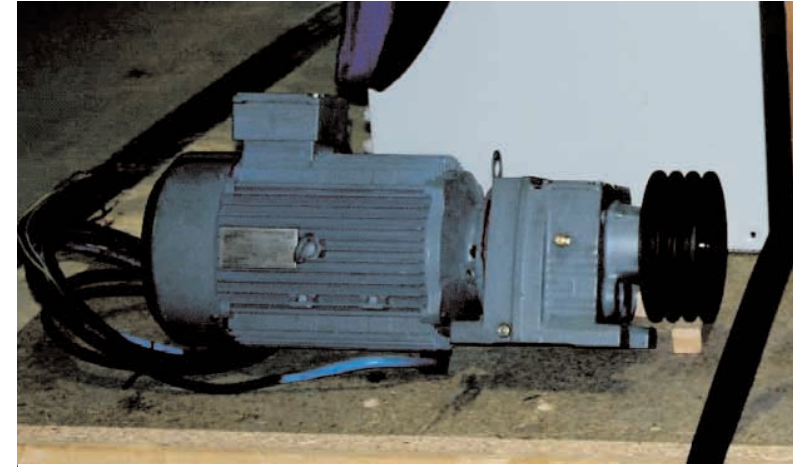

Fig. 10 Asynchronous motor with gearbox

The asynchronous motor and the gearbox is a driving unit of the unwinding mechanism. The transfer of power is done by V-belt gear. The motor is supplied by frequency changing unit with vector control. The need of the frequency-changing unit is due to the fact that the machine works in several modes in which different turns per minutes are requested. Also with respect to need of a run-up and a run-down ramp for loading rolls and unloading empty reels and due to securing fluent start of paper unwinding it is necessary to use the frequency-changing unit. According to the customer's request, the ABB frequency changing unit, ACS 350-03E-08A8-4, is opted for. Following are the parameters of the unit: power of $4 \mathrm{~kW}$, nominal current of $8,8 \mathrm{~A}$, voltage $\mathrm{Un}=400 \mathrm{~V}, 50 \mathrm{~Hz}$. The frequency-changing unit is placed in a separate distribution panel R2, Fig. 11

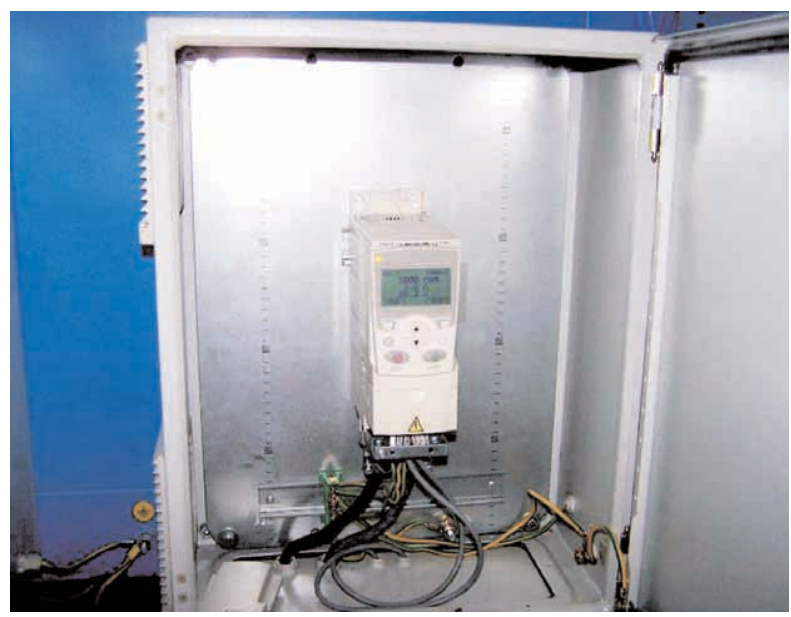

Fig. 11 Instrument panel $R 2$

A switchboard R1 shown in the Fig. 12 contains electrical devices, such as terminals, circuit breakers, switches, fuses, voltage transformer and supply $24 \mathrm{~V}$ DC, PLC automat, technological socket $230 \mathrm{~V}$ for connecting of computer for PLC programming. The upper side of the switchboard is used for control elements.

To ensure the automatic operation of the machine without the need of manual control it is necessary to equip the machine with 


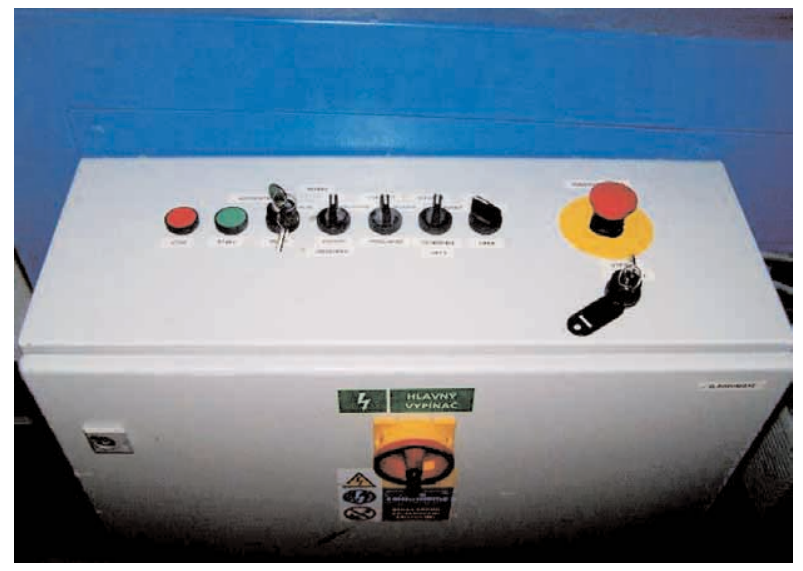

Fig. 12 Switchboard R1

a control unit. The control unit is PLC automat SIEMENS S7-222 with extension module for digital inputs and outputs EM 223. Signals coming from sensors and control elements go to PLC input. PLC automat then controls automat outputs connected to active elements or signalization. The outputs are switched on according to the pre-programmed sequences requested by technology. The PLC automat SIEMENS S7-2xx is programmed in the Step7 MicroWin environment. MicroWin allows to create virtual logical circuit (to program the PLC automat) and then to control the machine. The feature of the PLC automat to create virtual logical circuits enables debugging, testing or changing solution operatively with no need of mechanical changes in the system.

The machine was equipped with the following optical sensors according to the function requirements:

- optical sensor (transmitter - receiver) for detection of presence of a roll at a loading ramp,

- optical sensor (diffuse sensor with reflector) for detection of a roll by a device for loading a single roll to an unwinding unit,

- optical sensor (transmitter - receiver) for a roll detection at an unwinding V-belts unit,

- optical sensor (diffuse sensor) for detection of paper inserted under presser rollers,

- optical sensor (diffuse sensor with reflector) for detection of status of fullness of the box that stores empty reels.

There are also induction sensors in the machine, the function of which is to monitor position of pneumatic cylinders. One of the induction sensors has a safety function on the movable cover of the machine.

The machine can operate either in an automatic or a manual mode. If the machine operates in the automatic mode, a green signalization light starts flashing. When malfunction of the system occurs, the movable safety cover opens. The fact that a roll remains on the unwinding belts whilst the cover is open, is not in line with the normal operational regime of the machine. Therefore the machine automatically stops and a red light starts lighting. Under the seamless automatic mode the machine performs a set of operations automatically according the actual need. At the beginning the machine waits until a roll is loaded at a loading station. As soon as a roll is loaded and an optical sensor detects it, a command is triggered towards the belts to start moving. The roll is then transferred to a guide unit - a loader, the function of which is to guide and load a simple roll at the time onto the unwind belts. At this stage the belts move at reduced speed that is required for guiding the end of paper under the pressure reels. If within a certain interval the paper is not detected and the paper is not inserted properly the machine stops and the red light starts flashing. The paper insertion is monitored by the optical sensors connected to the pressure reels. There are eight sensors to detect rolls of varied diameters. Immediately after the paper is led under the pressure reels, the machine increases the unwinding speed to maximum. The unwinding process is also dependent on the technology of further processing of unwound paper. It is important not to overload the machine for further processing. The unwinding speed is reduced again as soon as the optical sensors register no paper under the pressure reels when the reel is successfully emptied. The loader is positioned back to the load position. The induction sensors connected to the pneumatic cylinder send information to the PLC unit. The unit then reverses the movement of the belts and the empty reel is launched to the storage space where emptied reels are stored. The capacity of the storage space is controlled by an optical sensor and the fullness of it is signalized by orange light. When the unwinding unit is empty the process starts from the very beginning by loading a new roll. If a roll is at the loading plate but it is not transferred to the loader the orange light flashes.

In a manual mode the operator can control each operation individually.

\section{Pneumatic part of machine}

Pneumatic part is composed of two pneumatic cylinders. One cylinder controls the loader, the function of which is to assure loading one simple roll at a time to the unwinding unit. The second one controls the cover of the machine. Fig. 13 illustrates the pneumatic cylinders. A component part of the pneumatic cylinders are electro pneumatic double action valves. They open and close in accordance with signals transmitted from PLC unit and thus they control the pneumatic cylinders.

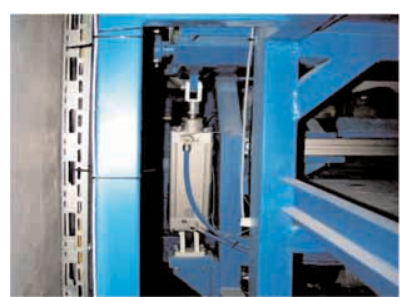

a)

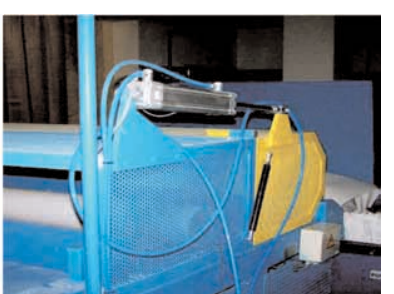

b)
Fig. 13 a) pneumatic cylinder - loader b) pneumatic cylinder - cover

In order to assure proper function of the pneumatic unit it must also contain: 


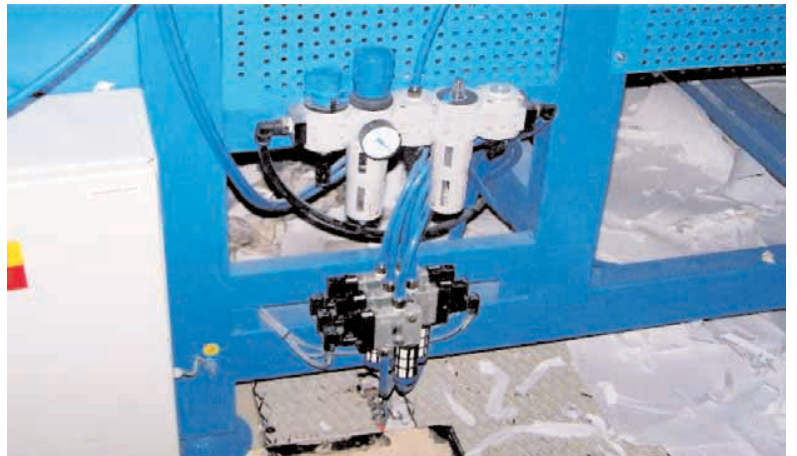

Fig. 14 Valve terminal

- a closing valve, which traps the compressed air in the pneumatic cylinders and releases pressure in the cylinders,
- a regulation valve, by regulation of which the pneumatic cylinders operate at constant pressure

- a lubrication set, that is needed for lubrication of the pneumatic cylinders which increases their durability.

Fig. 14 illustrates a valve terminal and a device for compressed air preparation.

\section{Conclusion}

Fig. 15 presents the final version of the unwinding machine after its installation in the Mondi BP paperwork. The operationtesting period was already done and the machine is prepared for full operation as soon as it receives a certification protocol from the Technical Inspection.
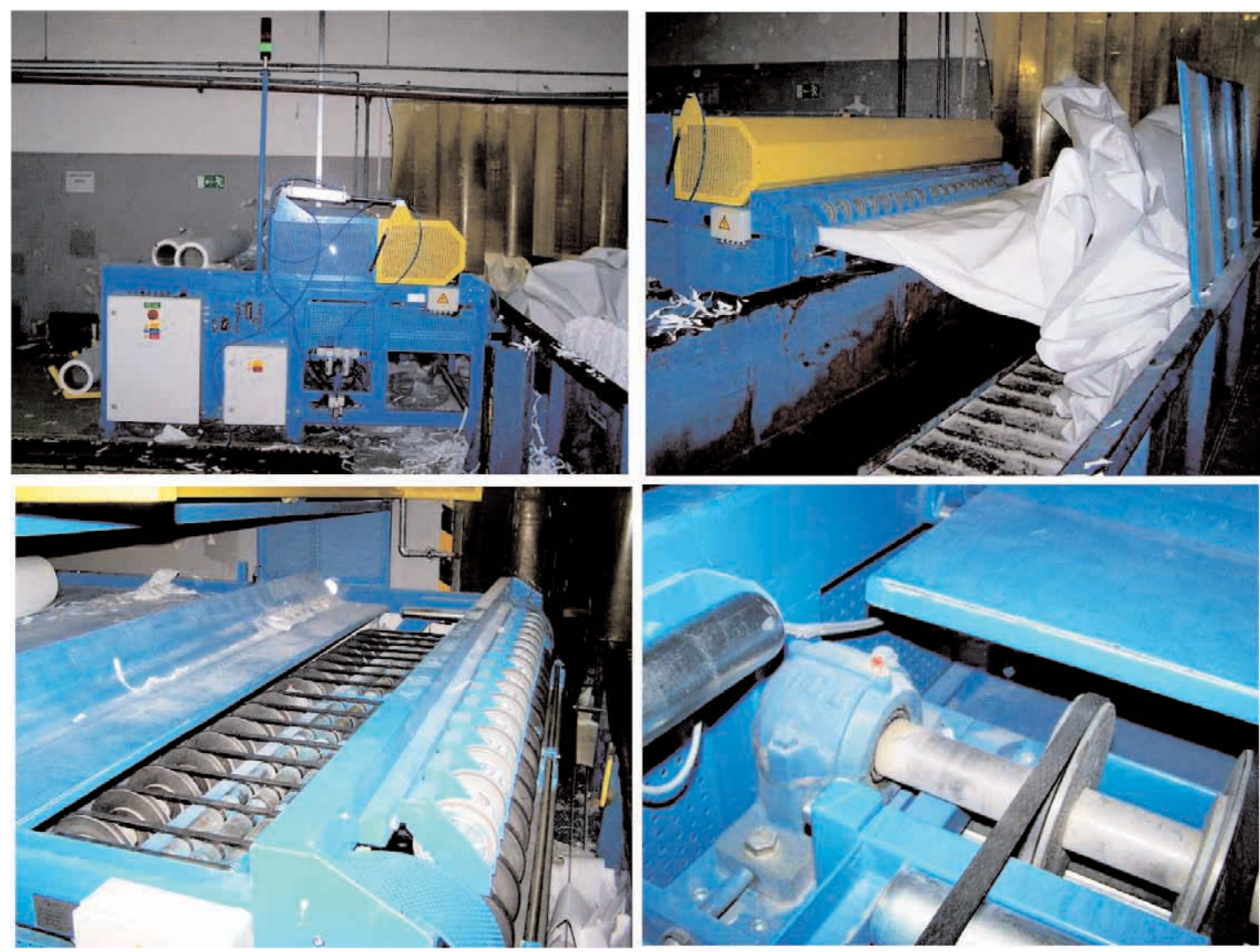

Fig. 15 Unwinding machine installed at the paperwork

\section{References:}

[1] BEDNÁRIK, B. et al.: Electroenergetics in Transport (in Slovak), ALFA Bratislava, 1983

[2] MÁLIK, L. et al.: Machine Elements and Mechanisms (in Slovak), EDIS Žilina, 2003, ISBN 80-8070-043-5,

[3] KUČERA, L., MAČUŠ, P.: The possibilities of 3D scaning for measurement of deformation of steel frames. XLV konferencia katedier častí strojov, Blansko, 2004, ISBN 80-214-2702-7. 